\title{
Modelling and simulations for signal loss evaluation during sampling phase for thermoluminescence authenticity tests
}

\author{
Anna Maria Gueli ${ }^{1}$, Martina Pace ${ }^{1}$, Stefania Pasquale ${ }^{1}$, Giuseppe Politi ${ }^{1}$, Giuseppe Stella ${ }^{1}$, Carlo Trigona ${ }^{2}$ \\ 1 PH3DRA labs, Department of Physics and Astronomy "Ettore Majorana", University of Catania \& INFN-CHNet Sez CT, via Santa Sofia 64, \\ 95123 Catania, Italy \\ 2 Department of Electrical Electronic and Computer Engineering, University of Catania, viale Andrea Doria 6, 95125 Catania, Italy
}

\section{ABSTRACT}

In authenticity tests using the thermoluminescence (TL) method, the sampling phase is fundamental to collecting an appropriate amount of powder for analysis. The powder is usually obtained by drilling in hidden and pertinently selected areas of an artefact. During the drilling, a local temperature increase can occur, and, because thermoluminescence emission is dependent on the heating rate, the authenticity test result could be invalidated due to underestimation of the signal intensity. In this work, the percentage of signal intensity loss is investigated through the combination of a dynamic electro-mechanical model and a typical TL glow curve simulation. After first modelling the drilling procedure to estimate the maximum temperature reached, the optimal parameters that should be used during the sampling phase are checked by simulations together with an evaluation of the correlated signal losses.

\section{Section: RESEARCH PAPER}

Keywords: Thermoluminescence; Drilling; Electrical measurements; Simulation; Glow curve.

Citation: Anna Maria Gueli, Martina Pace, Stefania Pasquale, Giuseppe Politi, Giuseppe Stella, Carlo Trigona, Modelling and simulations for signal loss evaluation during sampling phase for thermoluminescence authenticity tests, Acta IMEKO, vol. 10, no. 1, article 20, March 2021, identifier: IMEKO-ACTA10 (2021)-01-20

Editor: Carlo Carobbi, University of Florence, Italy

Received May 15, 2020; In final form February 26, 2021; Published March 2021

Copyright: This is an open-access article distributed under the terms of the Creative Commons Attribution 3.0 License, which permits unrestricted use, distribution, and reproduction in any medium, provided the original author and source are credited.

Corresponding author: Stefania Pasquale, e-mail: stefania.pasquale@ct.infn.it

\section{INTRODUCTION}

Thermoluminescence testing (TL) has for many years been a routine methodology for dating and verifying the authenticity of terracotta works of art. The assumption of TL is that a material absorbs energy during exposure to ionising radiation, which is then stored. The stored energy is released as visible light when the material is heated. This is due to the particular properties of natural dosimeters such as quartz mineral contained in ancient terracotta [1].

The crystal lattice of quartz $\left(\mathrm{SiO}_{2}\right)$ often presents trace impurities (i.e. aluminium ions, alkali ions and hydroxyl groups) and maintains a large number of complex defect configurations (such as dislocations and vacancy clusters). The lattice imperfections act as electron trapping regions when these charge carriers are activated to move through the crystal following ionisation by alfa, beta and gamma rays existing in nature. When a material containing quartz is heated to temperatures up to 500 $600{ }^{\circ} \mathrm{C}$, the binding between the imperfection and the electron may be upset, and the freed electron gives rise to photon emission during the return to its atomic site [1]. The heating of terracotta in a furnace resets TL accumulated by the quartz, and from this time on, TL begins increasing again until a new heating occurs. In the laboratory, the sample is reheated by a controlled heating process following a specific temperature rate $(\beta)$, and then the energy is released in the form of visible light (TL emission). The intensity of this photon emission ( $\left.I_{\mathrm{TL}}\right)$ as a function of the temperature is plotted in a glow curve that represents the most important result of TL measurements [1], [2].

The decay rate for an initial population $(n)$ of electrons in traps of a single activation energy (depth) using the Arrhenius equation according to the first-order Randall-Wilkins model [1] is

$$
\frac{d n}{d t}=-n s e^{-\frac{E}{k T}}
$$

where $n$ is the concentration of trapped carriers, $E$ is the activation energy of the trap $(\mathrm{eV}), k$ is the Boltzmann constant $\left(\mathrm{eV} \cdot \mathrm{K}^{-1}\right)$ and $T$ is the temperature of the sample $(\mathrm{K})$. [1] 


$$
s=\frac{\beta E}{k T_{m}^{2}} e^{\frac{E}{k T_{m}^{2}}}
$$

where $\beta$ is the temperature rate $(\mathrm{K} / \mathrm{s})$ and $T_{\mathrm{m}}$ is the temperature value related to maximum intensity of peak $(K)$. A glow curve of quartz is originated by the convolution of several peaks [3]-[7]. According to many authors, the precise temperature value of these peaks depends on the origin of the quartz analysed [8]-[10]. This represents the most important result of TL measurement [1], [2] and depends upon the material of the sample under examination.

The shape of each glow curve peak's intensity $\left(I_{\mathrm{TL}}\right)$, as described by equation (3), can be approximated by an analytical expression based on first-order kinetics where $I_{\mathrm{m}}$ indicates the TL intensity of the peak at temperature $T_{\mathrm{m}}[11]$ :

$$
\left.I_{\mathrm{TL}}(T)=I_{\mathrm{m}} e^{\left\{1+\frac{E}{k T_{\mathrm{m}}}\left(\frac{T-T_{\mathrm{m}}}{T_{\mathrm{m}}}\right)-e^{\left[\frac{E}{k T_{\mathrm{m}}}\left(\frac{T-T_{\mathrm{m}}}{T_{\mathrm{m}}}\right)\right]}\right.}\right\}
$$

For high quartz-concentration terracotta samples, four peaks at $T_{\mathrm{m}}=110^{\circ} \mathrm{C}, 230^{\circ} \mathrm{C}, 325^{\circ} \mathrm{C}$ and $375^{\circ} \mathrm{C}$ have been individuated. The $325^{\circ} \mathrm{C}$ and $375^{\circ} \mathrm{C}$ peaks are commonly used in TL dating because of their stability [12]. In this work, we consider these temperature values in the context of the cultural heritage applications of TL. The $110^{\circ} \mathrm{C}$ peak is not used directly in applications of TL in archaeomaterials because the traps and the electrons are unstable at environment temperatures, and thus the TL signal cannot build up over time. During the pottery's archaeological burial, the electrons trapped at imperfections, which are responsible for this TL peak, have long since escaped and decayed away under the effects of environment ground temperature [13]. This peak is used for pre-dose dating, which is a well-established experimental method for determining the dose in cases in which the $I_{\text {TL }}$ signal of a terracotta sample is affected by spurious signal and anomalous fading [14], [15].

The $I_{\mathrm{TL}}$ peaks at $T_{\mathrm{m}}=110^{\circ} \mathrm{C}, 230^{\circ} \mathrm{C}, 325^{\circ} \mathrm{C}$ and $375^{\circ} \mathrm{C}$ also play a fundamental role in authenticity tests performed by TL. Authenticity tests are used to distinguish between old (original) and new (fake) ceramic art objects through different sets of $\mathrm{I}_{\mathrm{TL}}$ measurement. These sets consist of heating at a constant rate $(\beta)$, recording the natural $I_{\mathrm{TL}}$ signals (natural glow curve) and then exposing the sample to a calibration dose of beta radiation, preferably at a level comparable to its natural dose. Finally, the calibration curve is elaborated and compared with the natural glow curve [16]-[18]. Data interpretation is a key phase, and many factors must be considered, above all the method of obtaining the sample to be authenticated. As stated above, the sample is collected in the form of powder by drilling at low speed in a hidden area of the artefact to be analysed. The use of drilling, which is necessary in order to speed up the procedure, has a main drawback of enhancing the local temperature and so possibly causing a diminishment of the $I_{\mathrm{TL}}$ signal due to its dependence on the heating rate. This is evident in equations (1)-(3). In particular, increasing the heating rate causes the intensity of the TL emission to decrease [19]-[23].

This underestimation can lead to erroneous results in terms of false negatives because the reduced $I_{\mathrm{TL}}$ signal from an authentic sample could be confused with noise, causing the artefact to be considered a fake.

Within the framework of measurement, TL is the object of several studies that seek to improve the capabilities of new architectures for automatic sensing and readout systems [24][28].
In order to assess the effect of drilling on the collection phase and thus on the results of authenticity tests, a multidisciplinary study is carried out and two studies have been proposed by the authors in [29] and [30]. Gueli et al. [29] presented preliminary research based on a non-invasive and in situ measurement methodology that estimated the temperature reached during the sampling. In particular, different conditions such as bit diameter, drill speed and interval time were explored. This method makes it possible to estimate the thermal energy dissipated during drilling through the measurement of an output voltage across a known resistor. The results were obtained on a pottery sherd, and the proposed solution is suitable to estimate the variation of temperature [29]. In Gueli et al. [30], the authors validated the indirect method through comparison with a standard direct method based on the acquisition of thermal images. The experimental data show a good agreement between both indirect and direct approaches, and an analysis regarding the role of the drill bits was pursued.

The results presented in Gueli et al. [30] fixed the basis for a more generalised model and a study of the effects of temperature on the TL authenticity tests. In this context, this paper addresses these specific points and improves the state of the art by presenting a more exhaustive model of the entire drill-based architecture that can simulate any loss of the TL signal due to heating during sampling.

In particular, by using a dynamic electro-mechanical model, it is possible to simulate the drilling procedure and estimate the maximum temperature reached during sample collection by measuring an electrical quantity. The simulations can also help to identify the optimal parameters to be used for the sampling phase.

Furthermore, the effects of the temperature reached during drilling in terms of TL signal loss in the collected sample have been simulated on the basis of the typical peaks of quartz crystalline inclusions.

\section{MEASUREMENT ARCHITECTURE AND MODEL}

A contactless measurement methodology was used to estimate the temperature during the drilling of an archaeological pottery sherd that was the object of a TL authenticity test.

Figure 1 shows the equivalent circuit of the drill [31], [32]. This section will present the measurement approach that was used to estimate, through an indirect method and by using a model, the temperature dissipated during the drilling procedure.

The left image of Figure 1 represents the excitation of the DC electric machine, which creates the static magnetic field used to move the rotor $(M)$ following the Faraday-Lenz principle. The image on the right represents the movable part composed of the rotor, the windings with resistance $R_{i}$ and the external DC voltage $V$. In the presence of this voltage, current $I$ will flow through the circuit and the rotor will start to rotate.

It should be noted that several losses occur in the system [33], and, in particular, the term $R_{i}$ will cause dissipation due to the
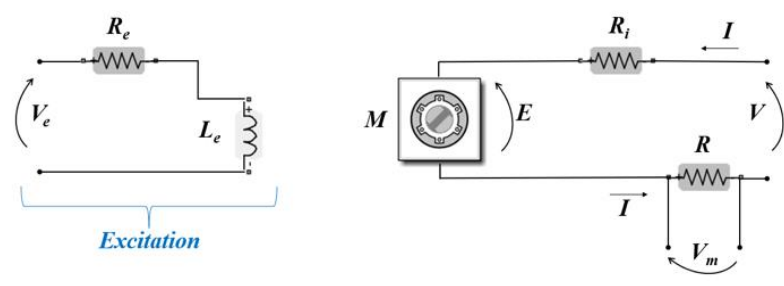

Figure 1. Equivalent circuit of the drill. 
Joule effect. By using the resistor $R$ and by measuring the voltage $V_{m}$, it is possible to estimate the temperature variation during drilling.

The energy balance equation in the rotor can be written as:

$$
V=K n_{r} \Phi+R_{i} I
$$

where $K$ is a constant that depends on the construction parameters of the machine (length, diameter, number of poles, type of windings, etc.), $n_{r}$ is the rotor speed and $\Phi$ is the excitation flux. By multiplying both members by the current $I$ (see equation $5)$, it is possible to write the balance equation in terms of powers. In particular, as shown in equation (6), the electrical power corresponds to the sum of the mechanical power and the power dissipated by the Joule effect.

$$
\begin{aligned}
& V I=K n \Phi I+R_{i} I^{2} \\
& P_{e}=P_{M}+P_{J}
\end{aligned}
$$

The mechanical torque $\left(C_{\mathrm{m}}\right)$, which is a consequence of the applied voltage $V$, is slightly smaller [31] than the electromotive torque $\left(C_{\mathrm{em}}\right)$ due to leakages caused by friction and ventilation as well as leakages in the iron. This mechanical energy, as shown in equation (7), corresponds to the product of the excitation flux $\Phi$, the current $I$ and the constant $K_{c}$.

$$
C_{\mathrm{em}} \cong C_{\mathrm{m}}=\frac{P_{M}}{\omega}=\frac{K n \phi I}{\omega}=\frac{K n \phi I}{2 \pi n} 60=K_{c} \phi I
$$

The mechanical balance equation can be written as:

$$
C_{\mathrm{m}}=C_{\mathrm{r}}+B \omega+J \frac{\mathrm{d} \omega}{\mathrm{d} t}
$$

where $C_{\mathrm{r}}$ is the resistive torque, $B$ is the viscous coefficient, $J$ is the moment of inertia, $\omega$ is the angular velocity of the rotor and $t$ is the time. In the presence of a mechanical load such as the drilling procedure, thermal energy $E_{\mathrm{T}}$ will be dissipated. The hypothesis of the method proposed here is that the work of the resistive torque is proportional to the thermal energy dissipated during drilling thanks to the temperature difference $\Delta T$ along the bit.

$E_{T}$ can also be expressed as a function of the measurand:

$$
E_{\mathrm{T}}=\Psi \lambda \frac{S \Delta T}{L} \Delta t
$$

where $\Psi$ is an experimentally estimated coefficient that is able to take the leakages into the account and to compensate the hypothesis of the model, $\lambda$ is the thermal conductivity of the bit material, $S$ is the contact surface, $L$ is the dissipation length, $\Delta t$ is a given time interval and $\Delta T$ is the physical quantity of interest.

The indirect estimation of $\Delta T$ can be accomplished by inverting the model above and setting the thermal power in proportion to the electrical power:

$$
\frac{E_{\mathrm{T}}}{\Delta t}=\frac{V_{\mathrm{m}}^{2}}{R}
$$

$\Delta T$ can thus be estimated as follows:

$$
\Delta T \approx \frac{V_{\mathrm{m}}^{2} L}{\Psi \lambda S R}
$$

As can be observed, in the absence of a mechanical load, the energy $E_{T}$ is equal to $0 \mathrm{~J}$. It is worth noting that by using equation (11) it is possible to estimate the value of the temperature variation during drilling. In fact, this condition will change the value of the mechanical torque, see equation (8), and, consequently, the value of the absorbed current $I$, see equation (7), and, finally, the voltage $V_{m}$. Through a differential measurement of $V_{m}$, it is possible to estimate the temperature difference $\Delta T$ along the bit.

Assuming that the initial temperature was room temperature, $\Delta T$ evaluation makes it possible to obtain the maximum temperature reached by the bit during drilling. This last causes the thermal energy transfer to the collected sample.

\section{GLOW-CURVE SIMULATION}

The aforementioned method was validated through the comparison between electrical measurements and infrared (IR) thermography image acquisitions [30]. The correlation between the maximum temperature estimated by the voltage measurements and the related IR images showed that the accuracy of the model corresponds to about $11 \%$.

The method determined the maximum temperature and the time to achieve it during drilling with different drill bits. According to the method, once the maximum temperature value is reached, it remains constant.

In the present study, the method is applied in three different experimental conditions with three metal bits with diameters equal to $2 \mathrm{~mm}, 3 \mathrm{~mm}$ and $5.5 \mathrm{~mm}$. With these three configurations, called Drill 2, Drill 3 and Drill 5, the maximum temperatures reached were $130^{\circ} \mathrm{C}, 82^{\circ} \mathrm{C}$ and $60^{\circ} \mathrm{C}$, respectively. Using these values and applying the Arrhenius relation, we looked for $I_{\mathrm{TL}}$ signal loss and then simulated the consequent glow curves based on the Randall-Wilkins model and the Podgorsak approximation [11].

The Arrhenius equation defines the probability per unit time of the release of an electron from the traps:

$$
p=s \cdot e^{\left(-\frac{E}{k T}\right)}
$$

where $p$ is the probability per unit time and $s$ is the frequency factor defined in equation (2); we consider this value to be $10^{-12} \mathrm{~s}^{-1} . E$ is the trap depth (the energy needed to release an electron from the trap), $k$ is the Boltzmann' constant $\left(8.617 \times 10^{-5} \mathrm{eV} / \mathrm{K}\right)$ and $T$ the absolute temperature. Table 1 shows the temperature values related to the maximum intensity of the quartz peaks $\left(T_{\mathrm{m}}\right)$ and the corresponding values of the trap depths $(E)$, which were used for the calculation of the TL intensity losses [34].

The glow-curve simulations have been performed using equations (1)-(3) with the parameters in Table 1 . A temperature range between $0-500{ }^{\circ} \mathrm{C}$ and a heating rate of $5{ }^{\circ} \mathrm{C} / \mathrm{s}$, corresponding to those typically used in a laboratory during an authenticity test, were considered.

The experimental TL glow curve used as reference was recorded using these parameters on an automated Risø reader model TL-DA-10 equipped with an EMI 9235QA

Table 1. Parameters used to simulate the glow curves: $T_{\mathrm{m}}$ is the temperature value related to maximum intensity of peaks; $E$ is the value of the trap depths.

\begin{tabular}{cc}
\hline $\boldsymbol{T}_{\mathrm{m}}\left({ }^{\circ} \mathrm{C}\right)$ & $\boldsymbol{E}(\mathrm{eV})$ \\
\hline 110 & 0.891 \\
230 & 1.170 \\
325 & 1.400 \\
375 & 1.510 \\
\hline
\end{tabular}


Table 2. For each quartz peak $\left(T_{\mathrm{m}}\right)$, the percentage of residual $I_{\mathrm{TL}}$ for the Drill 5, Drill 3 and Drill 2 experiments corresponding to $60^{\circ} \mathrm{C}, 82^{\circ} \mathrm{C}$ and $130^{\circ} \mathrm{C}$ sampling temperatures, using as reference the sampling performed at room temperature.

\begin{tabular}{cccc}
\hline $\begin{array}{c}\boldsymbol{T}_{\mathrm{m}} \\
\left({ }^{\circ} \mathbf{C}\right)\end{array}$ & $\begin{array}{c}\boldsymbol{I}_{\mathrm{TL}} \\
\text { Drill 5 } \\
(\%)\end{array}$ & $\begin{array}{c}\boldsymbol{I}_{\mathrm{TL}} \\
\text { Drill 3 } \\
(\%)\end{array}$ & $\begin{array}{c}\boldsymbol{I}_{\mathrm{TL}} \\
\text { Drill 2 } \\
(\%)\end{array}$ \\
\hline 110 & 57 & 38 & 0 \\
320 & 73 & 61 & 40 \\
325 & 78 & 68 & 50 \\
375 & 79 & 70 & 53 \\
\hline
\end{tabular}

photomultiplier tube. TL signals were detected using Corning 759 and Schott BG-12 optical filters.

\section{RESULTS AND DISCUSSION}

In Table 2, for each quartz peak $\left(T_{\mathrm{m}}\right)$, the percentage of residual $I_{\text {TL }}$ for the configurations Drill $2\left(130^{\circ} \mathrm{C}\right)$, Drill $3\left(82^{\circ} \mathrm{C}\right)$ and Drill $5\left(60^{\circ} \mathrm{C}\right)$ is listed. The values are expressed in terms of the TL intensity in the standard dating procedure, in which the powder of the sample is obtained by grinding the sample at room temperature.

These values are reported in Figure 2; the decreasing of TL intensity as a function of drilling temperature is evident, and the effect is stronger for lower TL peak temperatures.

The percentage of residual $I_{\mathrm{TL}}$ is significant for some peaks. The peak at $110{ }^{\circ} \mathrm{C}$ is very sensitive to temperature increase. In fact, at temperatures greater than $22^{\circ} \mathrm{C}$, the residual $I_{\mathrm{TL}}$ for this peak is $57 \%$ at $60{ }^{\circ} \mathrm{C}, 38 \%$ at $82^{\circ} \mathrm{C}$ and 0 at $130{ }^{\circ} \mathrm{C}$. This could have important consequences. For example, if a $2 \mathrm{~mm}$ diameter drill bit that reached a temperature of $130{ }^{\circ} \mathrm{C}$ was used during sampling, an artefact could be reputed as original despite it being a fake. Concerning the peaks at $325^{\circ} \mathrm{C}$ and $375^{\circ} \mathrm{C}$, two possible drawbacks could occur due to the low residual $I_{\mathrm{TL}}$ at high sampling temperature: a recent sample could be considered an original even if it was actually a fake, and, on the other hand, the expected age of an antique sample could be significantly underestimated.

Thanks to the glow curve simulation described in Section 3, we can directly see the effect of the signal loss on the TL signal. In Figure 3, we compare an experimental glow curve (No Drill) used for normalisation with those obtained at the different sampling conditions shown in Table 2 (Drill 5, Drill 3 and Drill 2).

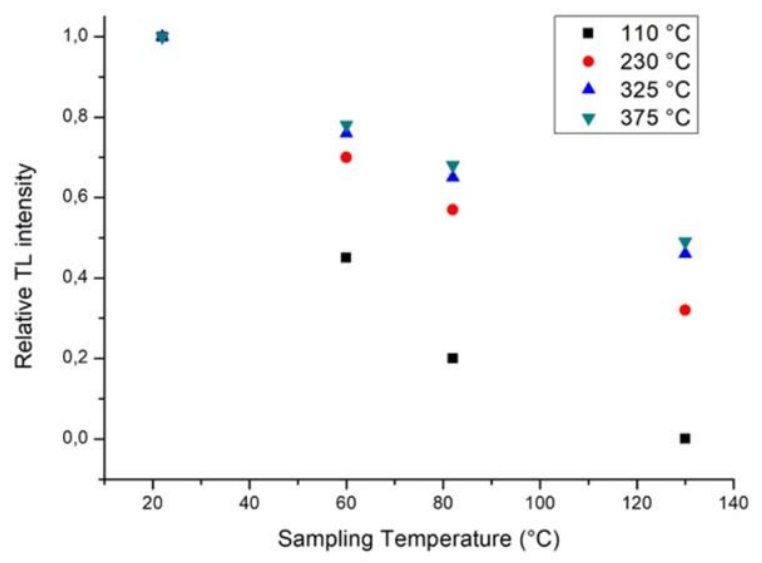

Figure 2. Intensity trend vs drilling temperature for all TL peaks.

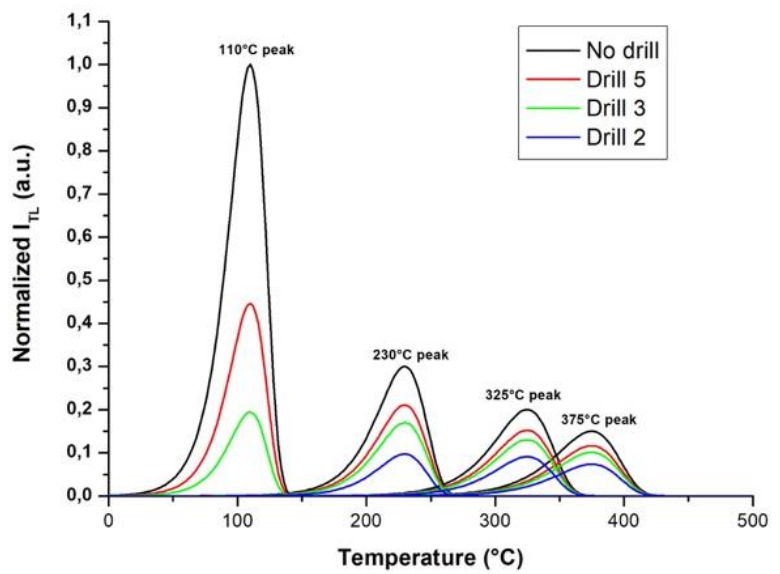

Figure 3. Comparison among the simulated normalised glow curves obtained for the different sampling conditions. The No Drill condition is obtained by the deconvolution of an experimental glow curve of an original terracotta sample.

The No Drill condition is obtained by the deconvolution of an experimental glow curve generated during a standard dating procedure used as reference.

\section{CONCLUSIONS}

Starting from an electrical and mechanical model, a method has been developed to apply during sampling for an authenticity test. By simulating the parameters at stake, this method makes it possible to evaluate the percentage of $I_{\mathrm{TL}}$ signal loss that could occur in TL measurements in the laboratory.

The temperature reached during sampling could be sufficient to compromise the results of an authenticity test. The $5.5 \mathrm{~mm}$ drill bit seems to be the best for powder collection because the temperature achieved during drilling with this bit is not high enough to significantly affect the $I_{\mathrm{TL}}$.

Although the actions performed during the collection phase depend on several factors, above all the intrinsic characteristics of the sample and the directives of the artefact owner in order to preserve the object, by our method it could be possible to determine the underestimation of $I_{\mathrm{TL}}$ in advance and thus make the opportune corrections during the data elaboration.

Our results indicate that, during sampling for an authenticity test, the size of the drill bit and the duration of powder collection must be marked because they can affect the TL test result. With this in mind, this research could be continued with further studies of drill sampling on ancient artefacts in order to endorse the method now proposed by recording and analysing experimental glow curves.

\section{REFERENCES}

[1] M. J. Aitken, Thermoluminescence Dating, Academic Press, London, 1985, ISBN 0120463814.

[2] S. J. Fleming, Thermoluminescence Techniques in Archaeology, Clarendon Press, Oxford, 1979, ISBN 978-1-4757-9696-4.

[3] M. David, C. M. Sunta, V. N. Bapat, A. K. Ganguly, Thermoluminescence of quartz. III: sensitization by pre-gamma exposure, Ind. J. Pure Appl. Phys. 16(4) (1978) pp. 423-427.

[4] R. B. Scholefield, J. R. Prescott, A. D. Franklin, P. J. Fox, Observations on some thermoluminescence emission centres in geological quartz, Rad. Meas. 23 (1994) pp. 409-412. DOI: $\underline{10.1007 / \mathrm{BF} 00215106}$ 
[5] P. Levy, Thermoluminescence studies having application to geology and archaeology, PACT 3 (1979) pp. 466-480.

[6] D. W. McMorris, Impurity color centers in quartz and trapped electron dating: electron spin resonance, thermoluminescence studies, Jour. Geophys. Res. 76(32) (1971) pp. 1896-1977. DOI: $10.1029 / \mathrm{JB} 076 \mathrm{i032p} 07875$

[7] D. M. Price, TL signatures of quartz grains of different origin, Rad. Meas. 23(2-3) (1994) pp. 413-417

[8] T. Hashimoto, N. Sugai, H. Sakaue, K. Yasuda, N. Shirai, Thermoluminescence (TL) spectra from quartz grains using online TL-spectrometric system, Geochemical journal 31(4) (1997) pp. 189-201.

DOI: $10.2343 /$ geochemj.31.189

[9] H. M. Rendell, P. D. Townsend, R. A. Wood, B. J. Luff, Thermal treatment and emission spectra of TL from quartz, Radiat. Meas. 23 (1994), pp. 441-449. DOI: $10.1016 / 1350-4487(94) 90077-9$

[10] W. J. Rink, Billion-year age dependence of luminescence in granitic quartz, Rad Meas. 23(2-3) (1994) pp. 419-422. DOI: $10.1016 / 1350-4487(94) 90074-4$

[11] E. B. Podgorsak, P. R. Moran, J. R. Cameron, Interpretation of resolved glow curve shapes in $\mathrm{LiF}$ (TLD-100) from $100 \mathrm{~K}$ to 500 K, Proc. 3rd Int. Conf. on Luminesc. Dosim., Risoe, Denmark, Oct. 11, 1971, pp. 1-8.

[12] A. J. Bos, Thermoluminescence as a research tool to investigate luminescence mechanisms, Materials 10(12) (2017) p. 1357. DOI: $\underline{10.3390 / \mathrm{ma1} 10121357}$

[13] D. K. Koul, $110^{\circ} \mathrm{C}$ thermoluminescence glow peak of quartz - a brief review, J. Phys. 71(6) (2008) pp. 1209-1229. DOI: $10.1007 / \mathrm{s} 12043-008-0177-\mathrm{y}$

[14] I. K. Bailiff, The pre-dose technique, Rad. Meas. 23 (1994) pp. 471-479 DOI: $10.1016 / 1350-4487(94) 90081-7$

[15] S. J. Fleming, The pre-dose technique: a new thermoluminescence dating method, Archaeom. 15 (1973) pp. 13-30. DOI: $\underline{10.1111 / i .1475-4754.1973 . t b 00074 . x}$

[16] S. J. Fleming, Thermoluminescence authenticity testing of ancient ceramics using radiation-sensitivity changes in quartz, Naturwissenschaften 59 (1972) pp. 145-151. DOI: $10.1007 / \mathrm{BF} 00637352$

[17] I. Liritzis, A. K. Singhvi, J. K. Feathers, G. A. Wagner, A. Kadereit, N. Zacharias, S. H. Li, Luminescence Dating in Archaeology, Anthropology and Geoarchaeology, Springer, Heidelberg, Germany, 2013, ISBN 978-3-319-00169-2.

[18] P. Craddock, Scientific Investigation of Copies, Fakes and Forgeries, Butterworth-Heinemann, Oxford, 2009, ISBN-10: 075064205X.

[19] H. F. Hornyak, R. Chen, A. Franklin, Thermoluminescence characteristics of the $375^{\circ}$ electron trap in quartz, Phys Rev B 46(13) (1992) pp. 8036-8049. DOI: $10.1103 /$ physrevb. 46.8036

[20] G. Kitis, E. Kaldoudi, S. Charalambous, Thermoluminescence dose response quartz as a function of irradiation temperature, Appl. Phys 23 (1990) pp. 945-949. DOI: $10.1088 / 0022-3727 / 23 / 7 / 030$

[21] A. V. Sankaran, K. S. V. Nambi, C. M. Sunta, Progress of thermoluminescence research on geological materials, Proc. Indian Nat Sci. Acad. 49(1) (1983) pp. 18-112.

[22] C. Schmidt, J. Friedrich, G. Adamiec, A. Chruscinska, M. Fasoli, S. Kreutzer, M. Martini, L. Panzeri, G. S. Polymeris, K. Przegietka,
P. G. Valla, G. E. King, D. C. W. Sanderson, How reproducible are kinetic parameter constraints of quartz luminescence? An interlaboratory comparison for the $110^{\circ} \mathrm{C}$ TL peak., Rad. Meas. 110 (2018) pp. 14-24.

DOI: 10.1016/i.radmeas.2018.01.002

[23] A. Chruscinska, H. L. Oczkowski, K. R. Przegietka, Trap spectra of annealed quartz, Acta Phys Pol A 89 (1996) pp. 555-568. DOI: $10.12693 /$ APhysPolA.89.555

[24] P. Neelamegam, S. Arumugam, Automated thermoluminescence measurement using microcontroller, IEEE Instrumentation and Measurement Technology Conference: Sensing, Processing, Networking, IMTC Proceedings 2, Ottawa, Canada, 19-21 May 1997, pp. 914-918.

DOI: $10.1109 /$ IMTC.1997.610258

[25] M. L. Mah, M. E. Manfred, S. S. Kim, M. Prokic, E. G. Yukihara, J. J. Talghader, Measurement of rapid temperature profiles using thermoluminescent microparticles, IEEE Sensors Journal 10(2) (2010) pp. 311-315. DOI: $10.1109 /$ JSEN.2009.2034023

[26] N. Bharathi, P. Neelamegam, FPGA based linear heating system for measurement of thermoluminescence, Measurement Science Review 11(6) (2011) pp. 207-209. DOI: $10.2478 / \mathrm{v} 10048-011-0035-9$

[27] M. L. Mah, P. R. Armstrong, S. S. Kim, J. R. Carney, J. M. Lightstone, J. J. Talghader, Sensing the thermal history of highexplosive detonations using thermoluminescent microparticles, IEEE Sensors 13(5) (2013) pp.1742-1747. DOI: $10.1109 /$ JSEN.2013.2242462

[28] P. Armstrong, M. Mah, H. Ross, J. Talghader, Individual microparticle measurements for increased resolution of thermoluminescent temperature sensing, IEEE Sensors Journal 18(11) (2018) pp. 4422-4428. DOI: $10.1109 /$ ISEN.2018.2823678

[29] A. M. Gueli, S. Pasquale, G. Politi, G. Stella, C. Trigona, Indirect temperature measurements for TL signal loss during drilling, Proc. of International Conference on Metrology for Archaeology and Cultural Heritage, Florence, Italy, 4-6 December 2019, pp. 522526. Online [Accessed 25 March 2021] https://www.imeko.org/publications/tc4-Archaeo2019/IMEKO-TC4-METROARCHAEO-2019-102.pdf

[30] A. M. Gueli, S. Pasquale, G. Politi, G. Stella, C. Trigona, TL authenticity tests: comparison between measurement methods for temperature estimation during drilling, Int. Jour. Cons. Sc. 11(1) (2020) pp. 233-242.

[31] M. V. Bakshi, U. A. Bakshi, Electrical Machines I, Technical Publications, 2008, ISBN 8184314264.

[32] J. G. Webster, Electrical Measurement, Signal Processing and Displays, CRC Press, 2003, ISBN 9780429214417.

[33] B. Szabados, A. Mihalcea, Design and implementation of a calorimetric measurement facility for determining losses in electrical machines, IEEE Transactions on Instrumentation and Measurement 51(5) (2002), pp. 902-907. DOI: $10.1109 /$ TIM.2002.806010

[34] R. K. Gartia, L. Lovedy Singh, Evaluation of trapping parameter of quartz by deconvolution of the glow curve, Rad. Meas. 46 (2011) pp. 664-668.

DOI: $\underline{10.1016 / \text { i.radmeas.2011.06.036 }}$ 